\title{
INTEGRATION OF UNDERWATER SONAR SIMULATION WITH A GEOGRAFICAL INFORMATION SYSTEM
}

\author{
Yanshen Zhu \\ School of Electrical Engineering and Computer Science \\ University of Central Florida \\ Orlando, FL 32816, U.S.A.
}

\author{
Serge Sala-Diakanda \\ Luis Rabelo \\ Jose Sepulveda \\ Maria Bull
}

\begin{abstract}
This paper discusses the integration of a geographical information system (GIS) with a simulation model of the sensors (active and passive) used as components of a detection system on US Navy ships. The simulation model is a tool developed to improve threat recognition, undersea tactical awareness, countermeasure emissions, and counterweapon fire control that enables surface ships to survive a salvo of torpedo attacks. The model, was implemented (2005-2006) in Java using AnyLogic ${ }^{\mathrm{TM}}$ (by XJ Technologies). A commercial GIS application provides data visualization, query, analysis, and integration capabilities along with the ability to create and edit geographic data. The simulation model runs and seamlessly gets geographical information from ArcGIS (by ESRI corporation) in order to make decisions such as avoiding a ship going aground. Statistics and animations are controlled by the simulation software, while the maps and the movements of the environment object above of the map is handled by ArcGIS.
\end{abstract}

\section{INTRODUCTION}

The evolution of weapon systems used by US and foreign Navy platforms make it relevant to develop a system that allows the US Navy to improve its threat-recognition systems. With the use of this tool, it is possible to avoid wasted anti-torpedo torpedoes in false alarms. In the same way, today, foreign Navy platforms are harder to find and they possess a wider array of weapons (Vining 1999). When Navy ships are operating closer to the littoral, landbased objects, and sound behavior in both shallow waters or against the coast add to the difficulties of quickly and precisely detecting threats which may be a danger to the survival of the ship.

\author{
Dept. of Industrial Engineering \& Management Systems \\ University of Central Florida \\ Orlando, FL 32816, U.S.A.
}

Related research has been conducted on threat recognition and its related decision making (Blake and Hummel 2004; Jeffers, Breed and Gallemore 2000; Totir, Radoi, and Quinquis 2005; Wilson 2003). The modeling algorithms developed by researchers have helped to improve the effectiveness of the ship's sensor systems. The US Navy uses a set of sensors classified as either passive or actives sensors. These sensors are used to detect and classify all objects within a given detection range. The information from these sensors is then fused, and the final decision to react, or not to react is made. Sensor fusion technologies, such as using neural networks, have been developed (Boß et al. 2001) and are examples of the theory of evidence (Fabre, Appriou, and Briottet 2001).

Seabed characteristics also affect the accuracy of the ship's sensor in identifying a target. The classification of a threat depends on the interaction between seabed and target. Specifically, it will depend on type of seabed and bathymetry (marine growth, rocky structures) and the perturbations they will provoke on the target echo (Petillot, Reed, and Coiras 2006).

The following sections detail how we developed and integrated a simulation model that represents the behavior of undersea sonar with a geographical information system. A brief description of a navy ship's detection capability and how this capability is modeled is given in section 2 . The interface mechanism between the GIS system (ArcGIS Engine) and the simulation environment (AnyLogic) is explained in section 3. The simulation model details, its logic, its objects and the user definable parameters are described in section 4. The design of a scenario and the development of a GIS marine environment are handled in section 5. The fully developed system and some of its outputs are illustrated in section 6 followed by the conclusions in section 7 . 


\section{SENSORS MECHANISM}

A Navy ship tows an array of sensors; some passive and some active. Sensors are used to detect and classify all objects within a given detection range. Sensors include radar, sonar, infrared and optic sensors. Ships also carry integrated surface picture capabilities to reduce the false alert rate. Around the ship, a detection area is defined. Its range is sensor-dependent.

Passive sensors (PS) are highly sensitive but not very specific. Passive sensors "listen" for signals and classify the emitting source as harmless or potentially threatening. They detect most signals but interpret a significant number of harmless signals as potential threats.

Active sensors (AS) offer greater accuracy in detecting threats. However, the "ping" issued by an active sensor also makes the vessel visible to potential enemies. Signals acquired from passive sensors are fused with data from the active sensors. If a signal is classified by the PS as potentially threatening, a second (active sonar) sensor is engaged to make a determination. If the active sonar confirms the hostile nature of the signal, radar is asked to verify whether the signal is generated by a surface vessel. If the radar does not "see" the source of the signal above water, a torpedo attack is assumed and a decision is made through Fire Control to intercept and destroy the perceived threat. The active sensors allow for detection, classification and localization of up to 4 threat torpedoes and provide targeting data for Anti-Torpedo Torpedoes (ATTs) through reception of high power source echoes, acoustic interception of active transmissions, and resolution of bearing ambiguity.

\section{THE SIMULATION ENVIRONMENT AND GIS SYSTEM INTERFACE}

Two systems are integrated in this effort. The first system, AnyLogic ${ }^{\mathrm{TM}}$, a simulation software developed by $\mathrm{XJ}$ Technologies, was used to develop and implement the simulation model. AnyLogic ${ }^{\mathrm{TM}}$ was selected, among other reasons because it is based on Java, an object-oriented programming (OOP) language. OOP is desirable as it allows reusability, extensibility, and maintainability of the built model. This is the main model, in which the entire simulation resides.

The second system, an ArcGIS Engine, was used to provide GIS services (maps and querying capabilities) to the simulation model and to display dynamically the simulation outputs. The ability to access and use real geographic data from a geographic information systems database constitutes a natural evolution of our simulation model. As the simulation runs, its objects (the different ships and animals) routinely request geographic information with respect to their positions. Depending on the information provided, such as proximity to land, other ships, or shallow water, the simulation model may modify the at- tributes (such as their course) of some objects. ArcGIS Engine then uses this information to dynamically update the display of the simulation.

\subsection{AnyLogic}

AnyLogic ${ }^{\mathrm{TM}}$ is one of the most popular simulation software packages on the commercial market so it will not be discussed in detail. It can model complex hybrid, discrete and continuous systems. It provides not only the software, but also a set of application programming interfaces (APIs) for the user to develop their model. (XJ Technologies 2007)

\subsection{ArcGIS Engine}

In a commercial GIS application, all spatial data is geographically referenced to a map projection in an earth coordinate system. Therefore, as demonstrated in this simulation model, multiple types of data from various heterogeneous sources, such as navigational hazards and ships trajectories, can be seamlessly integrated, using a series of layers which are all projected to the same coordinate system. In our application, marine data was obtained in the form of shapefiles which were viewed and manipulated in ArcMap, the main visualization software of ArcGIS.

The ArcGIS Engine is an ESRI product specifically designed for developers. It provides a standard framework for developing stand-alone GIS applications. ArcGIS Engine provides extensive access to the ArcObjects, upon which the ArcGIS Desktop products are built.

The ArcGIS Engine provides developers access to a vast set of GIS software components and a set of visual controls that permit the use of many properties, events, and methods. With that, developers have the capability to develop focused, industry specific access to GIS from within familiar software applications. They can build their applications with their special requirements and embed their GIS logic in non-GIS-centric applications. Deployment of applications developed with ArcGIS Engine requires only a ArcGIS Engine Runtime or ArcGIS Desktop license per computer, which is very cost-effective. (ESRI, 2007)

\subsection{Integration}

Even though ArcGIS Engine is developed in $\mathrm{C}++$, it provides wrapped APIs for different programming languages, such as .NET, and Java. ArcGIS Engine is used to provide the GIS services and the geographic information of the environment. Based upon the information provided, the ships schedule their routines. ArcGIS Engine is also used to display the location of the objects such as ships, animals, fish, etc. ( See Figure 1). 


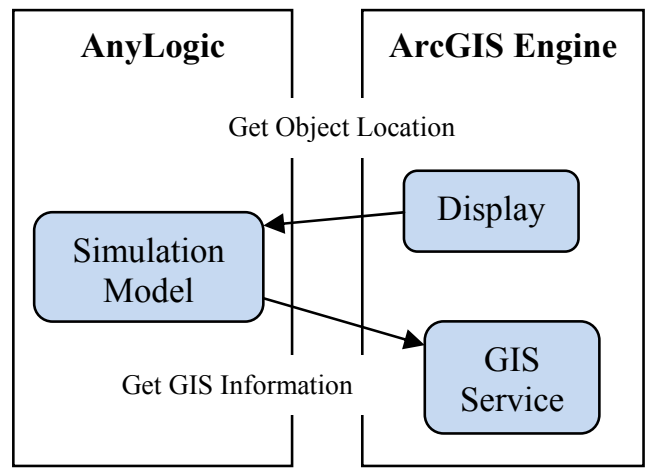

Figure 1: Integration of Anylogic and ArcGIS Engine

\section{MODEL DETAILS}

The goal of the simulation model is to assess the effectiveness of individual sensors and the sensor system as a whole. The details of the simulation design and performance were previously reported (Sepulveda et al. 2006). A brief summary follows.

The simulation model activates one ship (it has the capability to activate more ships) and defines (for each activated ship) the available sensors and their corresponding sensitivity and specificity for each target type. It also assigns to each ship a patrol route (heading and speed) and a complement of ATT. The ship scan within its detection range while it patrols.

The simulation then randomly creates harmless and threat objects according to user-specified probability distributions. Most of the objects will be false targets, neutral ships or large marine animals. Neutral ships have a heading and a speed, animals have random behavior.

Detected objects are tracked of on the display. When an object is detected, the sensors classify it. If the passive sonar classifies the object as a potential threat, a secondary (active sonar) sensor is activated. If the threat is confirmed, the radar is asked whether the target is visible above water. If the radar does not see the object, the target is engaged. See Figure 2.

Occasionally, there is a false alert, e.g., a situation where the passive sensor detects a potential threat which the active sensor and the radar fail to classify correctly, thus resulting on a wasted ATT.

Occasionally an enemy tries to get within range and launch a torpedo attack. The passive sonar tries to detect and correctly classify the threat. If the passive sonar fails to detect the enemy ship, there is still a chance that it will detect the incoming torpedo. In either case, the active sensor is engaged and should confirm the presence of a threat and activate the radar. If the radar confirms an underwater threat (torpedo) the ship's fire control room engages the attacking torpedo when it gets within the response range.

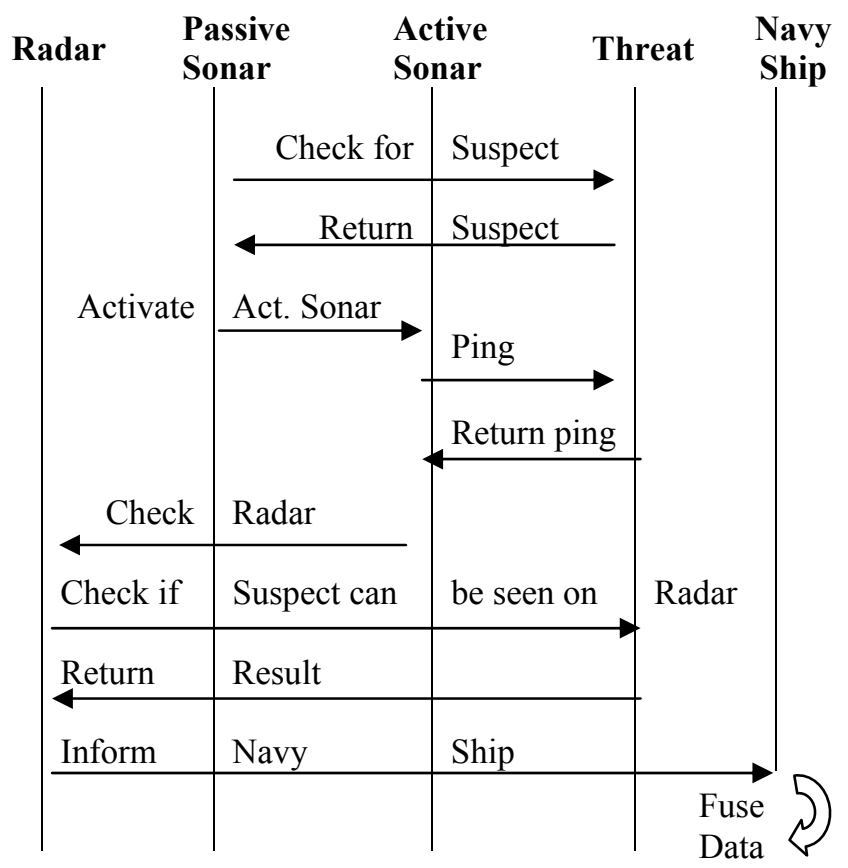

Figure 2: Sensor detection

Sensor sensitivity (the proportion of signals from a threatening source correctly classified as threats) and sensor specificity (the proportion of signals from a harmless source correctly classified as harmless) are important measures that can also allow the Navy to decide whether a newly developed sensor device is worth deployment. See Figure 3.
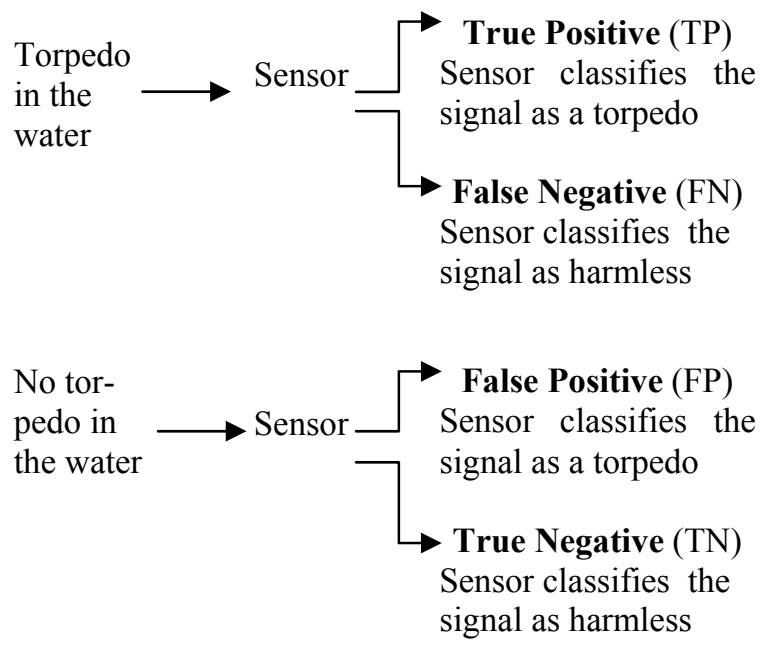

Figure 3: Possible situations

The simulation keeps track for each sensor and for the ship itself (e.g., the collection of sensors working as a unit) of the false positives (no torpedo attack but sensors indicated the presence of a torpedo), true negatives (harmless 
signal classified by the sensors as harmless), true positives (attack detected by the sensor), and false negatives (attack classified as harmless by the sensors).

The sensitivity and specificity concepts may be extended to multiple devices (passive sonar, active sonar, and radar) working as a coordinated set (e.g., the decisions made in the ship's fire control room). See Figure 4.

Sensitivity - The ability to detect a treat

Sensitivity $=\mathrm{TP} /(\mathrm{TP}+\mathrm{FN})$

Sensitivity $=1$ if $\mathrm{FN}=0$.

We do not miss any torpedo.

Specificity - The ability to react to real threats only Specificity $=\mathrm{TN} /(\mathrm{TN}+\mathrm{FP})$

Specificity $=1$ if $\mathrm{FP}=0$

We do not fire ATTs at harmless objects We react correctly to all false alarms!

Efficiency system $=(\mathrm{TP}+\mathrm{TN}) /(\mathrm{TP}+\mathrm{FP}+\mathrm{TN}+\mathrm{FN})$ Fraction of signals (objects) correctly classified

Figure 4: Sensor sensitivity and specificity

Objects are disposed of when they exit the system boundaries. Information is written to a file indicating whether the object traveled through a detection zone and, if so, if it was detected by the passive sensor.

The simulation ends after the available ATT are exhausted or all present ships are hit by the enemy. The user can end the simulation at any time by using the "stop" button provided.

In addition to providing the sensitivity and specificity of each sensor, the same Measures of Performance are provided for the ship.

\subsection{The Environment}

In the original simulation model (Sepulveda et al. 2006), the environment was represented as a vast ocean area In the current version, the main difference is that the environment is no longer a vast ocean without land masses. The simulation now included over a realistic geographical area. The model's current scenario is the Atlantic Ocean near the North-East coast of the United States, a region for which sea bathymetry characteristics are readily available. As modeled, ships move on a map of a pre-defined geographical area. The size of this area is defined as 2100 square nautical miles (but size can be user defined). The measure of distance is expressed in nautical miles, and speed in expressed in knots $(1$ knot $=1$ nautical mile per hour). This is valid for every modeled object in the platform.

\section{SCENARIO AND DEVELOPMENT OF A MARINE ENVIRONMENT}

\subsection{Integration of the Simulation and GIS}

The approach taken to integrate the Simulation Model and ArcGIS, a Geographical Information System, is summarized in Figure 5. The ArcGIS engine provides layers for the maps and databases. Specific information is gathered from several sources.

\section{Integration of the information}

ArcGIS

(Integrate geographical resources

- Generate ready-to-use map.

- Generate ready-to-use database)
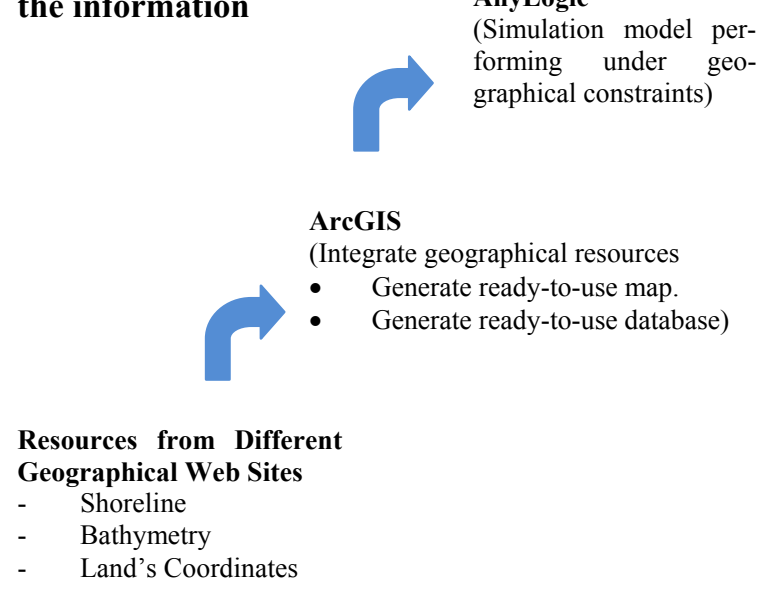

Figure 5: The integration of the simulation and GIS

\subsection{Selection of a Geographical Area}

The selection of a geographical area in which to evaluate the performance of the above model was largely influenced by two criteria: (1) the availability of marine data necessary to develop the geographical maps to be used by the ArcGIS Engine (as discussed in section 5.3) and (2) the navigational complexity of the area due to the presence of commercial ports and major seaways.

In the North-Atlantic, the United States coast spanning from the state of Virginia to the state of the New York fulfills the two criteria just mentioned. The bay near the Port of New York/New Jersey for example is the largest port complex on the East Coast of North America. It has at least 7 major marine terminal and 7 cargo terminals (The Port Authority of NY \& NJ, 2007). The bay is located at the hub of the most concentrated and affluent consumer market in the world, and is a main intersection of major commercial seaways (shown in Figure 6). According to the US Army Corps of Engineers U.S. Waterway Data (US Army 
Corps of Engineers, 2007), this North-Atlantic region contains more than 760 coastal and inland ports (shown in Figure 7). It is also noteworthy that two of the major US Navy ports, are both located in the area, in Norfolk, Virginia.

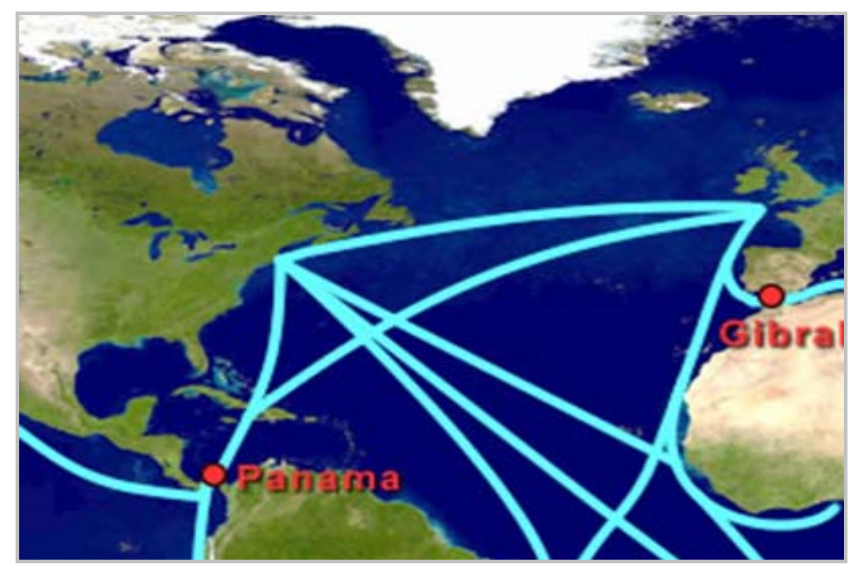

Figure 6: Major transatlantic seaways (Michigan Tech 2007)

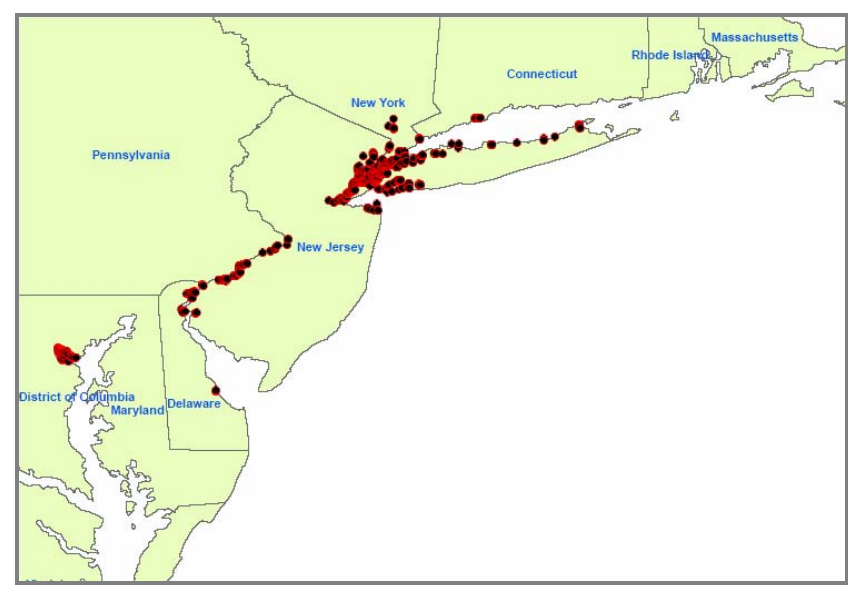

Figure 7: Coast and inland ports of the Northeast United States plotted in ArcMap (US Army Corps of Engineers, 2007)

\subsection{ArcGIS Capabilities}

ArcGIS Desktop provides data visualization, query, analysis, and integration capabilities along with the ability to create and edit geographic data (ESRI 2007). The data may originate from different sources. It may be provided either as (1) Shapefiles (maps which can be viewed and manipulated in ArcMap the main visualization software of ArcGIS Desktop) or (2) Tables (such as ports locations which necessitate the development of layers before they can be used in ArcGIS).
ArcGIS also provides a set of projection tools which are used for two main purposes: (1) Assign an earth coordinate system to a shapefile if the shapefile was provided without one, and (2) project shapefiles which have different coordinates systems to a common coordinate system. Projections are a necessary step particularly when map editing tasks are anticipated, as is the case here.

\subsection{Data Collection and Map Development}

Nautical charts such as the Electronic Navigation Charts (ENCs) provided by the National Oceanic and Atmospheric Administration (NOAA, 2007) provide detailed representations of the U.S. coastal and marine environment, resulting in hundreds of spatial feature attributes. NOAA groups this data into 8 main categories, which are listed in Table 1.

Table 1: Categories of ENC data

\begin{tabular}{|l|l|}
\hline Category & Brief Description of Data Contained \\
\hline Caution & $\begin{array}{l}\text { Natural or man-made object or areas } \\
\text { which demand caution from the mari- } \\
\text { ner }\end{array}$ \\
\hline Depth & Bathymetric data, varying water depth \\
\hline $\begin{array}{l}\text { Harbor Instal- } \\
\text { lations }\end{array}$ & $\begin{array}{l}\text { Man-made marine installations and an- } \\
\text { chor points for vessels }\end{array}$ \\
\hline Infrastructures & $\begin{array}{l}\text { Bridges, pylons and artificial water- } \\
\text { ways }\end{array}$ \\
\hline Navigation & $\begin{array}{l}\text { Man made devices such as lights, radio } \\
\text { stations and floating objects for naviga- } \\
\text { tion aid }\end{array}$ \\
\hline Regulated Area & $\begin{array}{l}\text { Generally restricted area, due to mili- } \\
\text { tary practices, dumping ground of } \\
\text { harmful material, etc. }\end{array}$ \\
\hline $\begin{array}{l}\text { Time Varying } \\
\text { Objects }\end{array}$ & $\begin{array}{l}\text { Areas of Earth magnetic field anoma- } \\
\text { lies }\end{array}$ \\
\hline Topography & $\begin{array}{l}\text { Coastline, Shoreline, and other land- } \\
\text { form data }\end{array}$ \\
\hline
\end{tabular}

Although all this data is important for navigation purposes, some may not necessarily be of interest for the simulation model. For example, data in the Navigation category (man made devices such as lights, radio stations and floating objects for navigation aid) is not important to our simulation so this data was not considered. This was also the case with the Harbor Installations and Time Varying Objects categories (they would have significantly increased the modeling complexity if implemented but only added marginal benefits to the outcome of this study).

Out of the remaining five categories, the Depth and Topography categories were given the greatest priority for this stage of the simulation model. These categories have the two most impact on sonar performance.

Bathymetry contours data for the east coast was obtained from the US Geological Survey (USGS 2007). The 
data, as shown in Figure 8, is a shapefile of type polyline with water depth recorded in 250 meter increment.

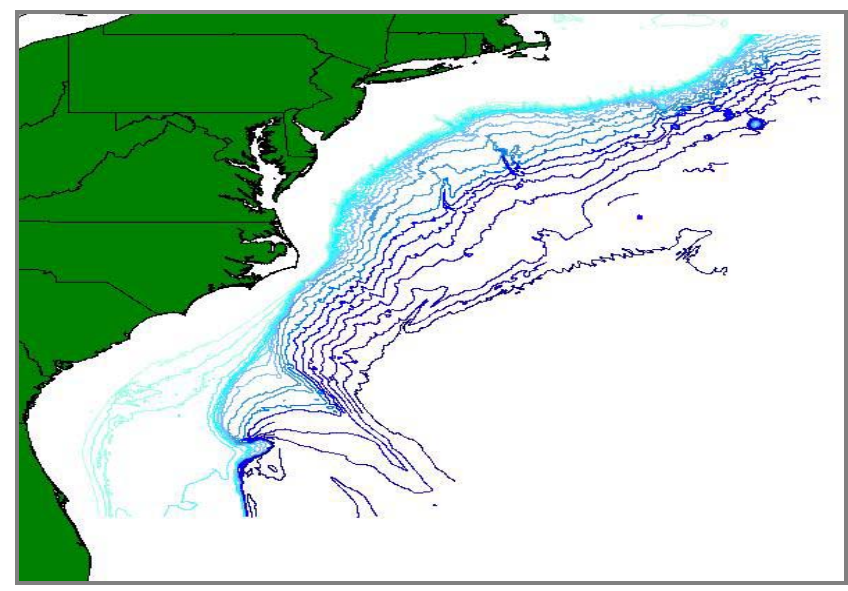

Figure 8: Bathymetry contours in 250 meter increment for the coast of the United States (USGS 2007)

Coastline data was obtained from the U.S Census Bureau (2007) in the form of a cartographic boundary file of the continental United States, which is a shapefile of type polygon. More refined shoreline maps may be obtained from sources such as the Historical Shoreline Database of NOAA (NOAA 2007). However, this level of detail was not considered necessary for this stage of the simulation model.

Using the editing tools available in ArcGIS, a new shapefile which includes land masses, a water area to represent the Atlantic ocean, and water depth information was developed. This shapefile possesses two attributes which are queried by the simulation model: (1) SURFACE, a boolean with values "water" or "land" and (2) DEPTH, a numerical attribute containing the bathymetry data.

A land mass has a DEPTH value of 0 . The shapefile developed is shown in Figure 9. It represents a marine environment extending approximately $1,200 \mathrm{~nm}$ in the eastwest direction and $1,200 \mathrm{~nm}$ in the north-south direction. At an average speed of 25 knots, the marine environment is sufficiently large to simulate any Navy ship patrolling during a 24-hour period.

ArcMap provides editing capabilities instrumental in developing the marine environment with all the characteristics desired, e.g., definition of surface type (Land, Water). Before advancing after a simulation step, a ship checks whether the destination is water (in which cases it moves) or land (in which case it changes direction). See Figure 10.

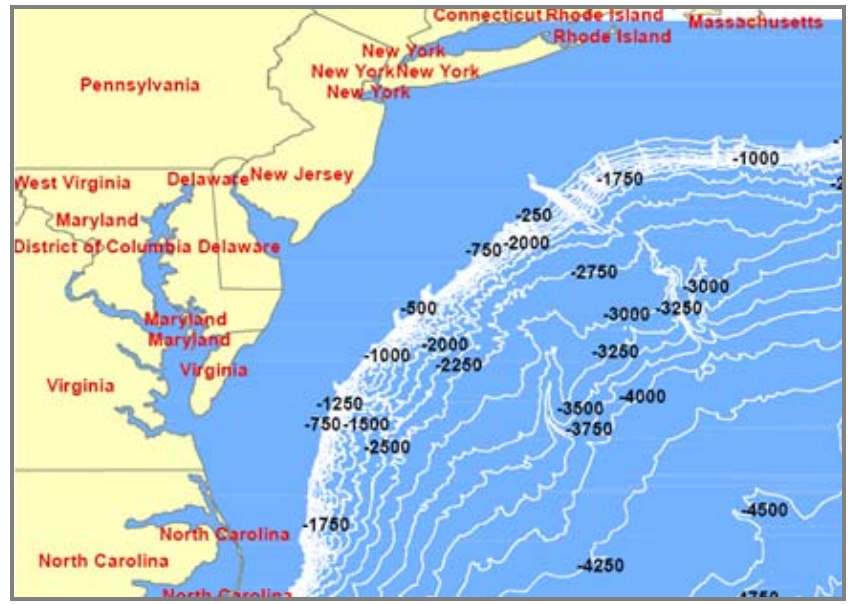

Figure 9: North-Atlantic marine environment

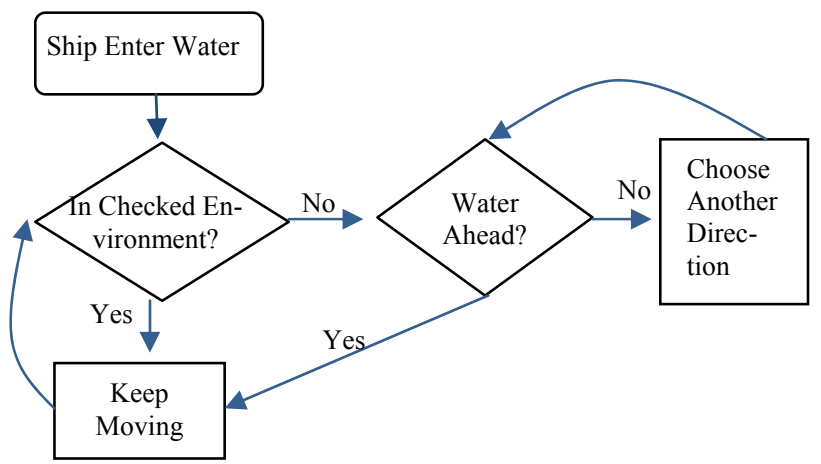

Figure 10: Ship's navigation activity diagram

\section{RESULTS}

Figures 11 and 12, show typical simulation screens. Figure 11 is the parameter panel through which the user can modify the simulation parameters. Figure 12 is the animation window which displays the interactions of the system, such as discovery, tracking, anti-torpedo firing etc.

The simulation ends when (1) the ship is destroyed, (2) the ship runs out of ATTs or (3) the user stops it manually by clicking on the Stop button in the screen's lower left corner.

As indicated in Figure 11, Navy ships are denoted by a green dot, a civilian ship is a blue dot and an enemy ship are denoted is a yellow dot. A marine animal is represented by an icon of a whale. Ports are represented by a red circle on the coast.

During the simulation, when an object is detected by the ship's passive sonar, the corresponding icon is surrounded by a dark blue circle. If the sonar activates the active sonar and the object is pinged, a green circle appears around it. The circle changes to red if the radar detects the object .

The bottom part of Figure 11 shows the statistics of the simulation at runtime, including those of the individual 
sensors and system. The number of undetected harmless and threat objects, defined as those that have passed through the detection area without being detected, are also shown on this panel and constantly updated throughout the simulation run. The total number of ATTs left and the simulation time are also displayed. At the end of each simulation run, detailed statistics are shown in Tables such as the ones shown in Figure 13 and Figure 14.

For planning and tracking purposes, corresponding Excel files are created that contain: (1) Details related to the state of each object (such as being destroyed or out of bounds) and (2) details related to the performance of each sensor. The statistics collected can later be used for further analysis.

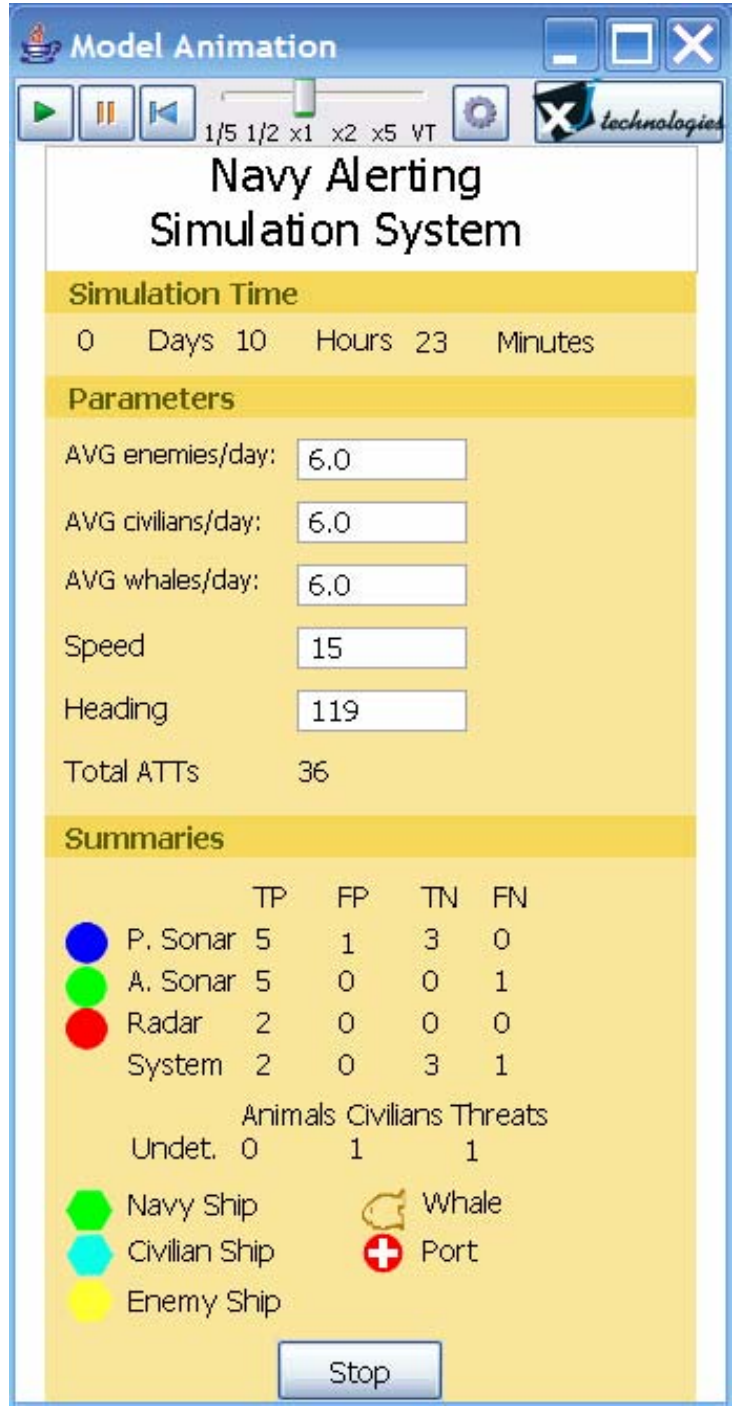

Figure 11: Simulation parameter control panel



Figure 12: A simulation scenario.

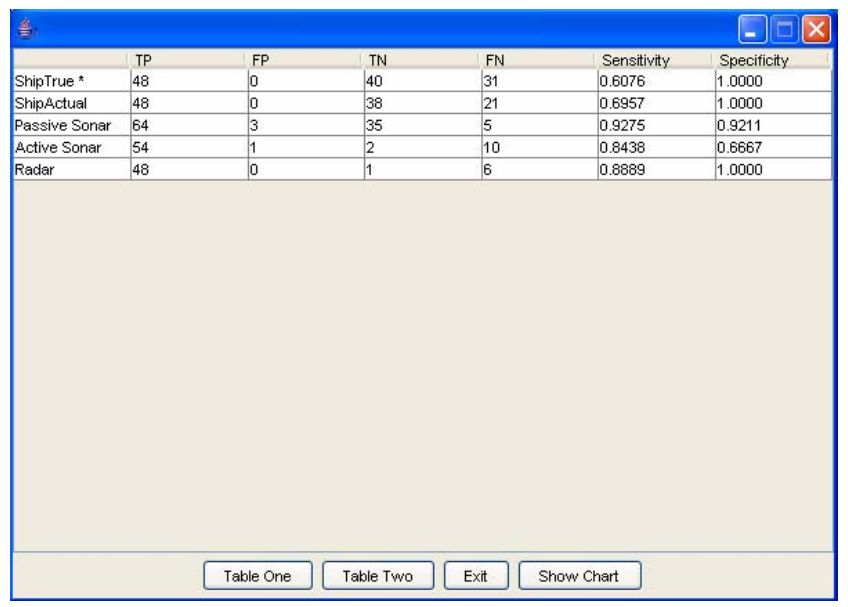

Figure 13: Simulation statistics for sensor $\&$ system

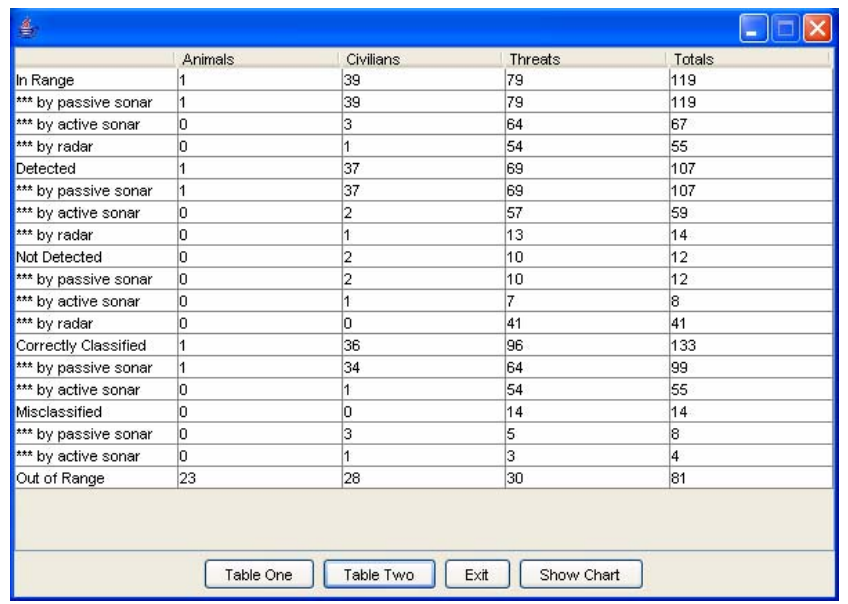

Figure 14: Simulation statistics for each object type 


\section{CONCLUSIONS}

This work integrates an object-oriented simulation model and the ArcGIS Engine. The platform produces a number of Excel files that record the individual behavior for each object generated during the simulation runs at the end of the simulation process.

The simulation model interacts with a geographical information system to obtain position data (avoiding a ship impact on the land) and seabed conditions. All the different objects interact with the geographical information system. All the objects schedule their routines and movements based on the environment information provided. Then, the main model locally modifies the position of each object and generates a detection probability depending on the geographical characteristics. Next, the model introduces the new positions and targets on the real map provided by ArcGIS.

The methodology provides a fast means for building of reusable and reconfigurable models of the different systems needed for the evaluation of a threat detection system, its components, and its operational methods in different geographical scenarios.

Our current work is focusing on the followings:

- Modeling potential degradations such as adding problematic bathymetry which confuses sensors.

- Developing procedure/script to analyze the behavior of sensor fusion schemes

These additions will create a higher level of fidelity which is more adequate to evaluate new sensors and support the decision making process.

\section{ACKNOWLEDGMENTS}

This research project, "Simulation Modeling Environment to Measure Sensors Effectiveness Using GIS Information and Sensor Fusion," has been conducted thanks to the funding of the Office of Naval Research. The project manager is Mr. Michael Vaccaro, Office of Naval Research, 875 North Randolph Street Suite, Code 321US, Arlington VA 22203-1995, (703) 588-0615 1425.

\section{REFERENCES}

Blake, W. D. and J. R. Hummel. 2004. Establishing human performance (Decision making) and natural environment consistency across integrated naval simulations. 72nd MORS Symposium.

Boß, T., V. Diekmann, R. Jürgens, and W. Becker. 2001. Sensor fusion by neural networks using spatially represented information. Biological Cybernetic 85:371385.

ESRI, GIS and Mapping Software. Available via <http://www.esri.com/index.html> [accessed March 25, 2007]
Fabre, S., A. Appriou, and X. Briottet. 2001. Sensor fusion integrating contextual information. International Journal of Uncertainty 9:369-409.

Jeffers, R., B. Breed and B. Gallemore. 2000. Passive range estimation and range rate detection, Sensor Array and Multichannel Signal Processing Workshop. Proceedings of the 2000 IEEE: 112-116.

Michigan Tech. Available via

<http://techalive.mtu.edu/glmri/imag es/EarthMaritimeMap_Labels.jpg> [accessed June 20, 2007]

National Oceanic \& Atmospheric Administration (NOAA) Historical Shoreline Data. Available via <http://www.csc.noaa.gov/shoreline/d ata.html> [accessed March 28, 2007]

Petillot, Y., Reed S., and Coiras E., A Framework for evaluating underwater mine detection and classification algorithms using augmented reality. UDT Conference. 2006.

Sepulveda, J., Rabelo, L., Zhu, Y., and Akin H., 2006, Modeling the Effectiveness of Underwater Sonar, In Proceedings of the 2006 Winter Simulation Conference, ed .L. F. Perrone, F. P. Wieland, J. Liu, B. G. Lawson, D. M. Nicol, and R. M. Fujimoto, 672-679. Monterey, CA

The Port Authority of NY \& NJ. Available via <http://www.panynj.gov/DoingBusiness With/seaport/html/index.html> [accessed July 4, 2007]

Totir, F., A. Radoi and A. Quinquis. 2005. Validation of Complex Naval Target Models using Superresolution Imagery Methods. Oceans 2005-Europe 1: 50-55.

U.S. Army Corps of Engineers U.S. Waterway Data - Port and Waterway Facilities. Available via

<http://www.iwr.usace.army. mil/ndc/d ata/datapwd.htm> [accessed July 11, 2007]

U.S. Census Bureau - Cartographic Boundary Files. Available via

<http://www.census.gov/geo/www/cob/b dy_files.html> [accessed July 11,2007]

US Geological Survey - Bathymetry Contours. Available via

<http://coastalmap.marine.usgs.gov/r egional/contusa/eastcoast/atlanticco ast/data.html> [accessed July 11, 2007]

Vining, P.. 1999. What me worry? - The current state of surface ship torpedo defense. Naval Institute Proceedings.

XJ Technologies, Simulation Software and Services. Available via

<http://www.xjtek.com/anylogic/> [accessed March 25, 2007]

Wilson, J.H.. 2003. Detection and classification of submerged threats in very shallow water using the Quiet 
Interlude Processing System (QuIPS). Oceans 2003. Proceedings 3: 1669-1672.

\section{AUTHOR BIOGRAPHIES}

YANSHEN ZHU is a Ph.D. student at the School of Electrical Engineering and Computer Science of University of Central Florida where he received his M.S. degree in Computer Engineering in 2003. He received his B.S. degree from Wuhan University, China in 1998. His e-mail address is <yanshen_zhu@hotmail.com>.

SERGE N. SALA-DIAKANDA, Ph.D. is a research associate in the Department of Industrial Engineering and Management Systems at the University of Central Florida. He holds a B.S. in Aerospace Engineering from EmbryRiddle Aero-nautical University, a M.S. in Manufacturing Processes and Systems and a Ph.D. in Simulation and Modeling from the University of Central Florida. His areas of interest include information fusion, risk analysis of space operations, and modeling of complex systems. His e-mail address is <serge@mail. ucf.edu>.

LUIS RABELO Ph.D., is an Associate Professor in Industrial Engineering and Management Systems (IEMS) at the University of Central Florida. He received dual degrees in Electrical and Mechanical Engineering from the Technological University of Panama and Master's degrees from the Florida Institute of Technology (Electrical Engineering, 1987) and the University of Missouri-Rolla (Engineering Management, 1988). He received a Ph.D. in Engineering Management from the University of Missouri-Rolla in 1990 where he also did Post-Doctoral work in Nuclear Engineering. He also holds dual MS degrees in Aerospace Systems Engineering \& Management from the Massachusetts Institute of Technology (2001). His experience includes Ohio University, BF Goodrich Aerospace, Honeywell Laboratories, NIST, NASA, and MIT. His e-mail address is lirabelo@mail, ucf.edu>.

JOSE A. SEPULVEDA Ph.D., P.E., is an Associate Professor in IEMS at the University of Central Florida. He received an Ingeniero Civil Químico degree from the Universidad Santa María, Valparaíso, Chile, and MSIE, MPH, and Ph.D. (Industrial Engineering) degrees from the University of Pittsburgh. Dr. Sepúlveda's major areas of research interest are object-oriented simulation, risk analysis, catastrophe response, measuring and modeling training effectiveness, and applications of industrial engineering and simulation in health care. He has written two books andnumerous publications. His e-mail address is <sepulvedemail.ucf.edu>.

MARIA BULL is a Ph.D. student at the Industrial Engineering and Management Systems Department at the Uni- versity of Central Florida. She received her B.S. degree from Concepcion University, Concepcion, Chile, in 2000. Her e-mail address is <maitebullegmail.com>. 